\title{
CULTURA DO MEDO E DEMOCRACIA: UM PARADOXO BRASILEIRO
}

\author{
Débora Regina Pastana \\ Doutoranda pela Faculdade de Ciências e Letras - FCL da \\ Universidade Estadual Paulista - UNESP
}

\begin{abstract}
RESUMO
Esse artigo analisa a insegurança social presente na sociedade brasileira contemporânea. Essa reflexão busca compreender como o medo, no caso associado à criminalidade, se tornou tão evidente no período democrático recente da história nacional e de que maneira ele interfere nas relações sociais e nas políticas públicas de segurança.Esse alarme social é considerado, nesta análise, uma via simbólica para o autoritarismo que só subsiste com a degradação da sociabilidade e o enfraquecimento da cidadania.

Palavras-chave: Medo. Criminalidade. Democracia. Autoritarismo
\end{abstract}

\begin{abstract}
This article analyzes the social unreliability present in the Brazilian society contemporary. This reflection it searchs to understand as the fear, in the case associated with crime, if it became so evident in the recent democratic period of nacional history and how it intervenes with the social relations and in the public politics of security. This social alarm is considered, in this analysis, a symbolic way for the authoritarianism that only subsiste with the degradation of the sociability and the weakness of the citizenship.

Key words: Fear. Crime. Democracy. Authoritarianism
\end{abstract}

Cultura do medo, neste artigo, representa a somatória dos valores, comportamentos e do senso comum que, associados à questão da criminalidade, reproduz a idéia hegemônica de insegurança e, com isso, perpetua uma forma de dominação marcada pelo autoritarismo e pela rejeição aos princípios democráticos.

Quando afirmamos a existência de uma cultura do medo na atualidade, por exemplo, não estamos dizendo que o medo é exclusivo deste momento. Na verdade o medo sempre acompanhou o homem, haja vista a busca permanente de unidade, coesão e a organização em grupo para se fortalecer e se proteger, ou seja, para enfrentar e eliminar as causas do medo.

Sobre o assunto afirma o historiador Jean Delumeau (1999), que a sensibilidade ao medo é um componente maior da experiência humana, a despeito dos esforços para superá-la. Em seu livro História do medo no ocidente, Delumeau identifica algumas formas de medos coletivos ocidentais e afirma 
que independente do motivo que causa o medo a necessidade de segurança é fundamental e está na base da afetividade e da moral humanas.

É oportuno, portanto, visualizar o medo inserido nas transformações políticas e sociais mais recentes da nossa história, para relacioná-lo com suas justificativas e, a partir daí, verificar em que momento começou a se formar, no Brasil, uma verdadeira cultura do medo, no caso relacionada à violência criminal.

Atualmente o problema social da violência urbana torna-se secundário diante de um problema ainda mais pungente que é o medo generalizado e exacerbado do crime. $\mathrm{O}$ medo associado à criminalidade nas metrópoles como São Paulo tornou-se um problema que se incorporou ao modus vivendi da população urbana. É hoje um assunto valorizado pela imprensa e pelas autoridades, determinando mudanças no comportamento e hábitos sociais.

Cada vez mais, as cidades assumem feições ditadas por uma "arquitetura do medo" - muros mais e mais altos, cercas em volta das residências, sofisticados sistemas de segurança e alarme - assim como se verificam outros fenômenos correlatos: crescimento visível das empresas privadas de vigilância, elevada quantidade de armas de fogo em circulação, êxodo de zonas e regiões onde o risco de se transitar sozinho pressupõe-se b elevado, além de demais mecanismos de autoproteção. Diante disso, os indivíduos e as instituições moldam seus comportamentos à nova realidade e reorientam-se para conviver com o medo e a insegurança, sob a tensão e a expectativa de serem vítimas de ofensas criminais.

Tulio Khan (1999), sociólogo do Instituto Latino-Americano das Nações Unidas para a Prevenção do Delito e Tratamento do Delinqüente (Ilanud), afirma que o estresse e o medo por causa da violência têm provocado a perda da qualidade de vida. "As pessoas saem menos de casa, deixam de freqüentar cinemas, bares, restaurantes e os alunos deixam de freqüentar cursos noturnos."

Pesquisa do Ilanud (apud KHAN, 1999), indica ainda que 8\% dos moradores da capital têm armas de fogo em suas residências; $27 \%$ das casas e apartamentos têm fechaduras especiais para portas; $31 \%$ têm cão de guarda; $28 \%$ dos carros possuem alarmes e 23\%, trava de direção ou câmbio; $45 \%$ dos habitantes costumam evitar certas ruas, locais ou pessoas por questões de segurança. Outros 49\% sentem-se inseguros ao andar pela vizinhança depois de escurecer e $35 \%$ acreditam que poderão ser vítimas de tentativa de arrombamento em suas casas ou de assaltos nos próximos 12 meses.

Esse medo também faz com que os indivíduos tentem se equipar com tudo o que oferece a moderna tecnologia em termos de alimentação, informação, comunicação e lazer, evitando ao máximo sair de casa. Assim, 
desfrutam os fins de semana entre fitas de videocassete, telepizzas, jogos eletrônicos e hora a fio no telefone ou na Internet. Aos que não tem acesso a esse tipo de solução protetora e cara, sobra a televisão, com programações medíocres e alienantes.

De fato, como afirma Alba Zaluar (2000, p.251), o aumento real, ou percebido como tal, da violência criminal tem conseqüências no plano simbólico, econômico e político. "As novas imagens da cidade não estão mais associadas à utopia liberal da liberdade e da segurança, seja no Rio de Janeiro ou em São Paulo, e as pessoas estão perdendo as velhas virtudes cívicas civilidade, segurança, tato e confiança”.

Sobre este alarme social fala a revista $\mathrm{Veja}^{1}$, em reportagem feita em junho de 2000. Tal matéria jornalística alimenta o pânico pedindo socorro, afirmando que a criminalidade no Brasil bate recorde e apavora a sociedade; e concluindo que os governantes não conseguem vencer os bandidos. Conclusões semelhantes a esta ou frases como "estamos perdendo a chance de vencer a guerra contra o crime" ou "não importa o crime escolhido, o Brasil está sempre numa posição crítica" nos transmitem, por exemplo, a sensação de que o problema é estratégico. Antônio Carlos Magalhães, senador naquele momento, parecia concordar com o diagnóstico, sugerindo a intervenção das Forças Armadas ${ }^{2}$ no policiamento de rua.

A população recebe esse diagnóstico e procura profilaxias não menos absurdas. O Ministério da Justiça, ao encomendar uma pesquisa de opinião para avaliar o impacto da criminalidade na população, constatou que $50 \%$ dos moradores das capitais evitam sair à noite com medo dos assaltantes, $38 \%$ já não circulam por algumas ruas que consideram perigosas, $24 \% \mathrm{mu}$ daram o trajeto até a escola ou até o trabalho para se esquivar do contato com os ladrões e $15 \%$ da população evita conversar com estranhos e até mesmo com vizinhos. .

Tais comportamentos nos levam à ingênua conclusão de que os bandidos agem preferencialmente à noite, em pontos fixos, geralmente em locais que fazem parte do cotidiano de todos, podendo, em alguns casos, ser nosso próprio vizinho.

Essa mesma população aterrorizada busca equipamentos de segurança cada vez mais eficazes e perigosos para a proteção de suas casas, executivos andam armados, com coletes à prova de balas, e os cursos de defesa pessoal incrementam as várias formas de "violência defensiva". Além disso o medo

\footnotetext{
${ }^{1}$ Edição n. 23, 7 jul. 2000.

2 Até memso o Plano Nacional de Segurança Pública, lançado pelo presidente Fernando Henrique Cardoso no ano de 2000, previa o apoio das Forças Armadas às polícias no combate ao tráfico de drogas.
} 
também influencia a escolha de certos bairros ou tipos de moradia considerados mais seguros, acentua os cuidados pessoais com horários, trajetos, meios de locomoção e locais freqüentados.

Sobre o tema também escreveu Teresa Pires do Rio Caldeira (2000, p.12), em pesquisa que deu origem ao livro Cidade de muros: crime segregação e cidadania em São Paulo. Tal antropóloga revelou algumas formas recentes de segregação espacial oriundas da violência e do medo. Segundo Caldeira, a elite paulistana tem usado o medo da violência e do crime para justificar tanto as novas tecnologias de exclusão social quanto sua retirada dos bairros tradicionais de São Paulo.

Evidenciadas a partir dos anos noventa, as transformações urbanas provenientes deste estado de alarme social, produziram um novo padrão de segregação espacial. Justamente no período de consolidação democrática o medo, associado ao crime e à violência, gera uma série de novas estratégias de proteção e reação, dentre as quais a construção dos muros é a mais emblemática. Tanto simbólica quanto materialmente, essas estratégias operam de forma semelhante: elas estabelecem diferenças, impõe divisões e distâncias, constroem separações, multiplicam regras de exclusão e restringem movimentos.

Os enclaves fortificados, assim denominados por Teresa Caldeira, são espaços fechados e monitorados, destinados a residência, laser, trabalho e consumo. Podem ser shopping centers, conjuntos comerciais e empresariais, ou condomínios residenciais. Eles atraem aqueles que temem a heterogeneidade social dos bairros urbanos mais antigos e preferem abandonálos para os pobres, os "marginais", os sem-teto. Por serem espaços fechados cujo acesso é controlado privadamente, ainda que tenham um uso coletivo e semipúblico, eles transformam profundamente o caráter do espaço público.

A proliferação de condomínios fechados, por exemplo, coloca em evidência esta cisão social. Segundo o diretor da Empresa Brasileira de Estudos do Patrimônio (Embraesp), Luiz Paulo Pompéia, de 1999 para 2000 houve um aumento de $100 \%$ nos lançamentos de condomínios horizontais na Grande São Paulo. O número de empreendimentos subiu de 35 em 1999 para 70 em 2000 e 105 em 2001. Os primeiros condomínios surgiram nos Jardins e na Chácara Flora, bairros considerados nobres em São Paulo. "No começo, eram apenas empreendimentos para classes média e alta. A partir de 1999, passaram a ter padrões diversos, preços variados e se espalharam para a periferia e cidades vizinhas", relata Luiz Paulo $(2002)^{3}$.

\footnotetext{
${ }^{3}$ Noticiado no Jornal O Estado de São Paulo. Edição de 31/03/2002.
} 
Alphaville é um bom exemplo de condomínio fechado situado na região oeste da Grande São Paulo, que acabou se transformando em um bairro autosuficiente. Inspirado no conceito de cidade de contorno norte-americanas, Alphaville estende-se pelos municípios de Barueri e Santana do Parnaíba, ambos na grande São Paulo. Desde quando foi criado, em 1974, o conjunto vem aprimorando sua infra-estrutura e aumentando o grau de aceitação no mercado imobiliário brasileiro. O Complexo Urbanístico Integrado de Alphaville, como o bairro é oficialmente chamado, possui núcleos residenciais (catorze condomínios fechados de casas), núcleos comerciais (Alameda Araguaia, Centro Comercial de Alphaville, Centro de Apoio 1 e 2, e 18 do Forte Empresarial - Setor Comercial) e núcleos empresariais (Alphaville Centro Industrial e Empresarial 1 e 2, e 18 do Forte Empresarial). Apesar de não ter hospital nem cemitério, a infra-estrutura organizada de Alphaville dispõe de resgates médicohospitalares, juizado de pequenas causas, procuradoria, fórum e delegacia. A região também possui opções para entretenimento (Cine Teatro Alphaville, Alphaville Tênis Clube), dois shoppings, faculdade, vários bancos e escolas, além de três supermercados e um grande número de escritórios.

Toda essa infra-estrutura permite ao indivíduo permanecer sua vida inteira nesta pseudocidade padronizada e cercada de muros altos, onde tudo parece estar na mais harmoniosa felicidade. Esse indivíduo, por enquanto, apenas terá que nascer em outro lugar e, quando morrer, ser sepultado também fora dali. Parece ficção mas o que realmente acontece é o distanciamento total desse indivíduo com a sua cidade, resultando assim, na perda de identidade cidadã, principalmente no que se refere à responsabilidade social e cívica perante os demais cidadãos.

Além disso, os condomínios fechados não contêm diversidade social. Os moradores integram um grupo social homogêneo, com mesmo perfil sócio-econômico, padrão de consumo, gostos e hábitos. Isso é, no mínimo, perigoso, pois cria uma atmosfera onde a diferença pode ser interpretada como algo negativo e, por isso, repudiado. As gerações mais novas, criadas nesses condomínios, por exemplo, por não terem convívio com o outro, podem desenvolver atitudes anti-sociais graves como a formação de gangues de condomínios, já evidenciadas em São Paulo.

Um outro exemplo de enclave fortificado é o shopping center. Na década de setenta a cidade de São Paulo contava com sete shopping centers. Nos anos oitenta esse número subiu para dezesseis e assim progressivamente até que no ano 2000 a cidade já comportava cinqüenta empreendimentos desse porte (INSTITUTO DE ESTUDOS EMPRESARIAIS, 2000).

Idealizados para concentrar e incentivar o consumo, a opção pelo shopping, atualmente, também está relacionada ao item segurança. A atração 
por estes ambientes deve-se ainda a fatores como a busca pelo distanciamento do caos urbano e da violência. $\mathrm{O}$ fato é que hoje, ir ao shopping pode ter inúmeros significados, como cortar o cabelo, ir ao cinema, ao restaurante, dançar, engraxar os sapatos, fazer ginástica e até mesmo estudar. Embora o shopping não esteja totalmente imune a problemas como roubos ou furtos, a população assustada considera o shopping ainda mais seguro do que as ruas da cidade.

Seja como for, esses enclaves representam um espaço que contradiz diretamente os ideais de heterogeneidade, acessibilidade e igualdade que ajudaram a organizar tanto o espaço público moderno quanto as modernas democracias. Privatização, cercamentos, policiamento de fronteiras e técnicas de distanciamento criam um outro tipo de espaço público: fragmentado, articulado em termos de separações rígidas e segurança sofisticada, e no qual a desigualdade é um valor estruturante. No novo tipo de espaço público, as diferenças não devem ser postas de lado, tomadas como irrelevantes, negligenciadas. Nem devem também ser disfarçadas para sustentar ideologias de igualdade universal ou de pluralismo cultural. O novo meio urbano reforça e valoriza a desigualdade e a separação e é, portanto, um espaço público nãodemocrático.

Essa cultura do medo também gera alguns tipos de discriminação, algumas efêmeras outras duradouras, mas todas profundamente violentas. As consideradas efêmeras se devem ao fato de geralmente estarem ligadas a um determinado evento violento.

Um exemplo recente de discriminação efêmera foi mostrado na reportagem de Mariana Sgarioni (1999). Segundo a jornalista, os motoboys, desde a prisão "maníaco do parque" (assim chamado pela imprensa), sofriam esse problema diariamente. "Aqui não tem nenhum motoboy. Todo motoboy é ladrão e bandido. Nossos profissionais são chamados de motociclistas ou couriers", dizia um gerente de uma empresa de transporte de documentos entrevistado. Os motociclistas da companhia concordam. "Esse nome (motoboy) acabou ligado aos crimes do maníaco e a assaltos feitos de motocicleta”, dizia um motociclista entrevistado, que observava as mulheres fechando o vidro do carro e até avançando o sinal quando percebiam um motoqueiro se aproximando. Outro motociclista também relatou ter sofrido discriminação. "Outro dia, uma mulher me perguntou na entrada do elevador: você é motoboy? Então pode subir sozinho, eu espero o próximo.” Essas discriminações só duram o tempo em que a notícia sobre o evento

\footnotetext{
${ }^{4}$ Trata-se de Francisco de Assis Pereira, um criminoso sexual que atacou e matou aproximadamente vinte mulheres no Parque do Estado, em São Paulo, preso em 1998.
} 
criminoso permanece na imprensa, no entanto são capazes de provocar uma série de novos eventos criminosos contra os então sujeitos da discriminação.

Já a discriminação duradoura é baseada sempre em informações equivocadas, estigmatizando grupos considerados perigosos pela tradição criminosa associada ora pela etnia, ora pelo local de moradia, ora pela condição financeira etc. São as clássicas afirmações de que negros e pobres são mais propensos ao crime. No caso da violência criminal, exatamente como atesta o ILANUD (apud KAHN, 1998), percebe-se que os grupos sociais mais vitimizados são aqueles socialmente excluídos, desprovidos dos símbolos que caracterizam o "cidadão de bem" e revestidos pelos signos da marginalidade (pobreza, juventude, cor negra, morador da periferia da cidade etc.).

O fato de ser adolescente ou adulto jovem, dos 15 aos 24 anos, do sexo masculino, também representa risco para esse grupo social, conforme destaca Maria Cecília de Souza Minayo (1997). Em casos de homicídios envolvendo estes indivíduos, por exemplo, a sociedade não se importa em esclarecer a morte, porque no imaginário social essas mortes representam uma espécie de "limpeza" e de solução para o problema da violência e das questões sociais e econômicas do País. Suas vidas são sentenciadas sumariamente.

Ressalta-se que a imprensa tem parcela significativa de responsabilidade nesta estigmatização. No caso específico da violência criminal o processo de produção da informação, por um lado, não reflete a realidade e a intensidade dos eventos que deveria recobrir; por outro, adequa-se à concepção dominante de violência e de sujeitos violentos que a sociedade hegemonicamente retém em seu imaginário.

Recente estudo foi feito pelo ILANUD (apud KAHN, 1998), que comparou a forma como o crime é representado na imprensa com os dados coletados pelos órgãos oficiais.Seus resultados revelaram a magnitude e o sentido de algumas distorções, que terminam por influenciar a imagem da sociedade sobre a criminalidade. Segundo a pesquisa, os pequenos furtos e as lesões corporais (agressões) são, de longe, os delitos mais freqüentes nas estatísticas oficiais de criminalidade. "Mas quem se interessa em ler nos jornais sobre batedores de carteira ou brigas de marido e mulher? Estes delitos tendem a comparecer no noticiário somente quando existe algo de pitoresco e anedótico relacionado a eles. Uma carteira furtada passa a ser motivo de interesse jornalístico se a vítima é uma autoridade pública ou artista conhecido. Caso contrário, estes eventos continuarão esquecidos nos arquivos das repartições públicas”. Na outra ponta, figuram os assassinatos, os estupros, seqüestros e ações de traficantes de drogas, todos eles cobertos numa proporção bastante superior à sua participação no mundo do crime. 
Estas distorções, no sentido de superestimar os crimes violentos e organizados, certo tipo de criminosos ou circunstâncias do crime, são compartilhadas também por políticos e membros das forças policiais e, não raramente, acabam refletindo em políticas públicas igualmente distorcidas: orientações para tratar com maior rigor os migrantes e pobres, criação de grupos especiais anti-seqüestro, leis mais repressivas contra usuários de drogas ou contra crianças e adolescentes etc.

Enfim, o que se observa hoje é uma verdadeira cultura do medo, onde a busca pela proteção contra o crime torna-se, ao mesmo tempo, obsessão e produto Os valores legitimados pela coletividade que surgem em decorrência desta cultura começam a aparecer de forma sutil, como em pesquisas de opinião e manchetes sensacionalistas, para rapidamente se cristalizarem nas mais variadas formas de comportamento segregantes, ações discriminatórias e políticas públicas autoritárias.

Sobre este tema, recente estudo feito pelo sociólogo americano Barry Glassner (1999) nos remete à reflexão central deste artigo. Glassner afirma que nunca na história foi tão seguro viver, a longevidade bate recordes sucessivos, mas nunca o homem se sentiu tão inseguro. "Vivemos um dos períodos mais seguros da história da humanidade, mas somos tomados por medos exagerados" Nos EUA, segundo o sociólogo, as taxas de criminalidade são as mais baixas em 30 anos, mas o medo da violência está nas alturas. Em seu livro faz um alerta adequado à realidade brasileira: "Um dos paradoxos da cultura do medo é que ignoramos problemas sérios, que realmente geram perigo. $\mathrm{O}$ crescente abismo entre riqueza e pobreza mata muito mais do que doenças do coração, câncer ou assassinatos”.

Para nós brasileiros fica a seguinte questão: qual a ideologia presente nesta cultura do medo, a quem ela interessa e como ela é difundida?

Cultura é aqui entendida como a expressão das necessidades historicamente condicionadas de um grupo social e de seus indivíduos, e como referência à totalidade de características de uma sociedade. Partimos, todavia, da assertiva de Marilena Chauí sobre o papel fundamental da ideologia na sua construção. Vale dizer que a visão de mundo de determinada sociedade se mostra manipulável através da cultura, mais precisamente da hegemonia cultural que um segmento dessa sociedade exerce sobre outro. Necessariamente a cultura carrega uma ideologia, entendendo esta "como sistema de representações, normas e valores da classe dominante que ocultam sua particularidade numa universalidade abstrata" (CHAUI, 1989).

Em uma sociedade desigual e classista, a dominação se dá não somente através dos instrumentos de coerção, mas também pela difusão de uma visão de mundo, isto é, uma filosofia, uma moral ou um senso comum que 
favoreçam seu reconhecimento e consequentemente sua legitimidade. Enfim, o exercício do poder também se dá de forma hegemônica. Embora este artigo não verse especificamente sobre a perspectiva materialista, não podemos ignorar que as respostas culturais associadas ao medo do crime, embora não sejam homogêneas nas diversas classes sociais, representam um olhar hegemônico sobre o fato.

O empresário manda blindar o automóvel, transformando-o num veículo de segurança e proteção contra o eventual ataque de bandidos seqüestradores ou de assaltos nas esquinas. Na sua casa são colocados alarmes, câmaras de vídeo, portões automáticos, tudo como medidas preventivas. Mesmo com todo esse aparato ele ainda contrata segurança particular para defesa da sua vida e do seu patrimônio. Já o trabalhador levanta o muro de sua casa, coloca grades nas janelas, lanças no portão, cacos de vidro nos muros e, como segurança particular, arruma um cão raivoso e feroz.

Não há dúvidas de que a sensação de insegurança e de medo produz comportamentos diferentes dependendo da classe social observada.

A classe proletária tem mais desvantagens porque ao mesmo tempo em que é o setor privilegiado para recrutamento da criminalidade tradicional e a principal vítima, é ainda o setor mais vitimado pelo aparato repressivo-punitivo e o menos protegido pelo setor judiciário, além de ser estigmatizado segundo a famosa associação pobreza/criminalidade.

A elite, no entanto, é a que se sente mais ameaçada, embora seja constatado que na maioria dos casos isso não deriva de experiências ou riscos diretos. Freqüentemente a insegurança assume o valor de ameaça global ao modo de vida, ao lugar conquistado na sociedade, ao status e aos privilégios de que se goza.

Como vimos, as elites procuram abandonar, de várias maneiras, o espaço público (condomínios, ruas e inteiros bairros fechados, shopping centers vigiados, áreas de lazer exclusivas etc.) com uma lógica diametralmente oposta à da expansão dos direitos. "A sensação de segurança não depende tanto da ausência do crime mas da distância social"(CALDEIRA, 2000, p.19). O pobre também abandona o espaço público e, sem muitas opções, se aprisiona em sua moradia, saindo apenas para o trabalho e para o compromisso religioso.

Mesmo com todas essas diferenças, todos estes comportamentos são hegemônicos quando reproduzem a idéia de insegurança e disseminam o medo. Isso demonstra que o conceito de hegemonia é perfeitamente atual e conveniente para identificar os mecanismos de dominação política através da cultura.

Como explica Alba Zaluar (1995), as pessoas trancadas em casa, seja na favela ou no bairro de classe média, deixam de se organizar, pouco participam 
das decisões locais que afetam suas vidas e pouco convivem entre si. Ao invés, muitos trancafiam-se, armam-se e preparam-se para enfrentar os próximos perigos como se estivessem numa guerra. $\mathrm{O}$ resultado disso é um generalizado desrespeito pelas regras da convivência social, para não falar de regras fundamentais à segurança de todos e que afetam todas as classes sociais

Numa sociedade como a nossa, que se estrutura pela dominação de classe, é evidente que diversos graus de violência são exercidos sobre os grupos dominados. Uma destas formas de dominação é a de criar toda uma ideologia justificadora, que faz com que essa situação de autoritarismo seja vista como algo circunstancial e necessário. É diluir a opressão em contextos instáveis convencendo o oprimido de que ele está nessa situação não porque existem outros que o oprimem, mas porque vive em um ambiente hostil onde o preço de sua segurança é a arbitrariedade e o autoritarismo. Evidentemente, quanto mais convincente e estratificada é uma opressão, mais sofisticado e mais profundo é o emprego e o papel da ideologia justificadora, que chega a ser, às vezes, perfeitamente introjetado pelo oprimido, contribuindo de maneira fortíssima para a manutenção do status quo e servindo também de suporte para os casos em que é preciso recorrer a uma violência mais direta e mais explícita como forma de controle.

A cultura do medo é portanto retrato desta forma hegemônica de pensar sobre a criminalidade e a segurança pública atuais.

Refletindo a crença de que vivemos em um momento particularmente perigoso devido ao aumento da criminalidade violenta e a legitimação de posturas autoritárias que, de acordo com interesses políticos, são difundidas como capazes de solucionar este problema, permite a manutenção das práticas autoritárias mesmo em um contexto político democrático.

Nesse sentido Marilena Chauí, ao estudar o pensamento de Espinosa, afirma que "a permanência das explicações antigas, apesar de seus enganos agora percebidos, não resulta da obstinação, mas indica a emergência de uma figura que, prometendo a paz e a segurança, tangerá o rebanho amedrontado" (CHAUI, 1999, p.58). De fato, "os que são movidos por ambição dominam os que são movidos pelo medo".

É dessa forma que posturas autoritárias se consolidam em nossa sociedade e a cultura do medo nos mostra como o autoritarismo é interpretado e reproduzido. Essa cultura, como observa Marilena Chauí, vem configurar um o desejo pela segurança, identificada como ordem, suscitando o pavor quanto a tudo que pareça capaz de destruí-la internamente.

Barry Glassner (1999) também observa que o que está por traz da cultura do medo é a possibilidade de vender perigos imaginários como reais, justificando diferentes formas de defesa. 
Entre nós, de forma paradoxal, o medo e a insegurança neste período democrático, permitem ao Estado medidas simbólicas cada vez mais autoritárias, leis cada vez mais punitivas, legitimadas por demandas sociais de proteções reais e imaginárias, principalmente da elite.

Maria Cecília Teixeira e Maria do Rosário Porto (1998) explicam que nesse contexto de pânico, a violência é entendida como um saldo negativo e anacrônico de uma ordem bárbara que precisa ser controlada a qualquer preço ou como resposta a uma sociedade geradora de rejeições, de exclusões, expressão de xenofobia e de recusa do outro.

Como resultado, tem-se, por um lado, o fortalecimento de um imaginário da ordem, justificando uma dominação autoritária em potencial, uma diminuição dos espaços sociais, um isolamento gradativo e voluntário das vítimas prováveis, cujos resultados podem servir tanto como incentivador do individualismo característico das sociedades contemporâneas ou para a tribalização, vale dizer, para a organização grupos fechados, que, muitas vezes, tomam o aspecto de gangues.

Esse processo de racionalização também é acompanhado de uma potencialidade paradoxal. A violência institucional pretende ser sua própria negação, conduzindo a uma ideologia da "tranqüilização da vida social”. No entanto, dada sua potencialidade, essa violência pede certo grau de legitimação só alcançável através do pânico.

Atualmente observamos que a exigência fundamental desta sociedade aterrorizada é um rigor punitivo traduzido em penas severas para os transgressores e a criminalização generalizada de condutas. A cultura do medo que se criou em torno da criminalidade provoca um generalizado desejo de punição, uma intensa busca de repressão e uma obsessão por segurança. A lei passa a ser a "tábua de salvação" da sociedade e quanto maior for a sua dureza, mais satisfeita ela estará. A segurança torna-se plataforma política e algumas vezes a causa da derrocada de um governo. A promessa é sempre repressão.

Diante deste contexto paradoxal entre liberdades civis e repressão arbitrária da criminalidade manifesta-se, através da mais variadas formas, a dominação através do medo que dá legitimidade para atos e discursos políticos contrários à própria democracia.

Sobre o assunto Vera Batista (2001, p.4) afirma que o fim do "ciclo do autoritarismo militar" trouxe um aprofundamento do caráter genocida dos "regimes democráticos", nas políticas de controle social formais e informais, na virada do século. Para ela um projeto de aniquilação cultural e física está em andamento.

Analisando o processo de criminalização da juventude por drogas no Rio de Janeiro, Vera constatou como na transição da ditadura para a democracia 
(1978-88), com o auxílio luxuoso da imprensa, permitiu-se que se mantivesse intacta a estrutura de controle social, com mais e mais investimentos na "luta contra o crime”. E, o que é pior, com as campanhas maciças de pânico social, permitiu-se um avanço sem precedentes na internalização do autoritarismo. Segundo a socióloga "pode-se afirmar sem medo de errar que a ideologia do extermínio é hoje muito mais massiva e introjetada do que nos anos imediatamente posteriores ao fim da ditadura”.

Nesse momento é fundamental entender as particularidades da reabertura política brasileira. A institucionalização do regime democrático com a manutenção dos interesses políticos e econômicos das elites, e, por conseqüência, a continuidade do poder autoritário, são características que enfraquecem a sociedade civil brasileira, tornando suspeito os aparelhos democráticos do Estado.

Relembrando Boaventura de Souza Santos (1999, p.130), a dominação exerce-se, na prática, em complexas combinações com as características de outros espaços estruturais que não o da cidadania, o que confere grande particularismo à atuação do Estado (clientelismo, nepotismo, corrupção etc.)

No caso brasileiro o clientelismo ${ }^{5}$ e o autoritarismo ainda perduram como práticas políticas emperrando o exercício pleno da democracia e, consequentemente, a cidadania torna-se um expressão vazia, destituída de valor social.

De fato, nossa transição democrática foi, na realidade, uma transação onde as elites do regime autoritário negociaram a abertura política e garantiram a continuidade do poder através das próprias eleições diretas. Observase, portanto, que "a nova república se singulariza por ter vindo ao mundo sem importar uma quebra na forma do político” (VIANA, 1986, p.227).

Nesse contexto, nossa abertura política deve ser vista com reservas, admitindo primeiramente nossa precária democracia, caracterizada pelo sistema eleitoral desproporcional, pelo sistema partidário frágil e pela ausência do valor cidadania onde a sociedade age política e socialmente movida pelo clientelismo e pelo autoritarismo.

O Núcleo de Estudos da Violência da Universidade de São Paulo (USP) ressaltou em seu último relatório uma observação importante para iniciar uma discussão sobre estas questões, qual seja o fato das massas populares não terem participado das negociações para a reabertura política. "Esta exclusão prenuncia que o novo regime terá dificuldades em preencher uma das exigências da democracia: ampliar a participação da sociedade no processo

${ }^{5}$ O clientelismo seria, na visão de Boaventura, o resultado da interpenetração do espaço da cidadania e o espaço doméstico e, portanto, entre dominação e patriarcado onde exercício da cidadania são delegados informalmente à famílias oligárquicas poderosas.NTOS, 1999: 130) 
de tomada de decisão e fortalecer as formas de representação de interesses. Prenuncia também uma forte resistência da elite consolidada à presença das populações mais pobres na política e aos partidos políticos com raízes sociais." (PINHEIRO, 1999).

De fato, uma transição democrática onde o governo autoritário impõe as bases do acordo acaba garantindo aos conservadores legitimidade eleitoral, com discursos totalmente opostos aos interesses democráticos. Mas como esses políticos adquirem legitimidade? Como seus discursos podem responder aos anseios populares se a satisfação social ameaça o seu poder?

Estes políticos se aproveitam da pouca cultura democrática brasileira, da acentuada aceitação da incerteza, da instabilidade, da desigualdade, da normalização da violência e na pouca crença no funcionamento das instituições (PINHEIRO, 1999).

É justamente minando a competência cívica da sociedade que os regimes autoritários se consolidam e uma das formas observada por este estudo é justamente desviando a atenção do cidadão para seus reais problemas e disseminando a insegurança.

Para o autoritarismo deve-se eliminar as formas de organização da sociedade que possam atuar como grupos intermediários entre o indivíduo e o Estado. Umas das maneiras é exacerbar alguns problemas sociais e, o mais importante, atribuir à determinados grupos a responsabilidade por eles. Isso fica claro no que se refere ao problema da violência criminal urbana ,onde a insegurança pública é mostrada como um problema crônico (daí o surgimento de uma cultura do medo), e o responsável direto, reconhecido pela imprensa e pelo discurso político, é o delinqüente.

A "nostalgia de uma cidade sem crimes perdeu-se no tempo" (ADORNO, 1994), mas nem por isso a sociedade brasileira o encara como um fenômeno social. Como vimos a angústia é o sentimento contemporâneo e a insegurança abre espaço para a manipulação de idéias e até mesmo de comportamentos.

Dessa forma, o que se nota modernamente é um sentimento passivo de vitimização que reproduz uma visão maniqueísta da sociedade, em que os bons se transformam em vítimas indefesas dos maus, incluídos nesta categoria os supostos responsáveis pela segurança de todos. Daí as expressões: impunidade, ineficácia das normas e do judiciário. A sociedade sente-se vítima do bandido e do Estado pouco opressor.

Nesse contexto, a sociedade volta-se para o criminoso com fúria e como profilaxia para a criminalidade exige soluções severas e infalíveis.

O IBOPE (apud CARDIA, 1995), a pedido da Comissão Justiça e Paz de São Paulo, apurou que na cidade de São Paulo apenas 26\% dos entrevistados 
rejeitaram totalmente as graves violações dos direitos humanos. A tortura aos presos foi apoiada por $54 \%$ dos entrevistados.

Torna-se oportuna para a elite dominante essa visão que relembra a anomia durkeimiana. Sob esta ótica, segundo os criminólogos Antonio Garcia e Pablos de Molina (1992), o delito é visto como um enfrentamento formal, simbólico e direto entre dois rivais - o Estado e o infrator - , que lutam entre si solitariamente, como lutam o bem e o mal, a luz e as trevas. $\mathrm{O}$ problema da violência torna-se, neste contexto, peça importante na engrenagem da dominação através do medo, sendo sua existência contínua e alarmante fundamental para que o medo perpetue a dominação.

Ao observarmos, por exemplo,as distorções dadas pela imprensa ao fenômeno da criminalidade, vemos que a parcela de crimes que a imprensa noticia é muito inferior ao total de crimes cometidos na realidade, o que denota o seu interesse por vender duelos. Há quem os consome e há quem os produz.

Diante desta discutível realidade passada pela imprensa impera o desejo por punições, em especial punições mais rigorosas. Sobre esse fato ensina a jurista Maria Lúcia Karan (1994) que tais mecanismos ideológicos, que legitimam o poder punitivo do Estado, propagam a falsa idéia de que a imposição deste sofrimento irracional aos autores das condutas conflituosas ou socialmente negativas, que a lei define como crimes, pode trazer proteção, segurança e tranqüilidade. Alimentam e são alimentados com falsas crenças, partindo fundamentalmente da equivocada identificação da ação individualizada da criminalidade convencional como tradução da idéia de violência, identificação que se constrói através da manipulação de sentimentos provocada por uns poucos crimes mais cruéis que comovem e assustam a sociedade.

Outro fato relevante é que a existência de leis, ainda que severas, não é suficiente para garantir a segurança de todos, nem tão pouco a cidadania. Segundo Guillermo O'Donnell (apud PINHEIRO, 1999, p.37), a realidade necessita ser congruente com as leis, é preciso de fato viver a proteção das leis, receber tratamento justo das agências do Estado e proteção contra a violência delas A confiança de que as leis garantem a igualdade de tratamento necessitam que as instituições estejam a serviço dos cidadãos, que ninguém seja "dono" delas.

No Brasil, a sobrevivência da frase: aos amigos tudo e aos inimigos o peso da lei, revela a desigualdade e, principalmente, o uso arbitrário da lei. A lei é, muitas vezes, usada contra o cidadão, para garantir a dominação perpetrada.

Estes fatores explicam, por exemplo, porque os brasileiros são, entre os povos latino-americanos, aqueles que menos preferência tem pela democracia. 
Segundo pesquisa (PINHEIRO, 1999, p.36) realizada pelo IDESP em maio/ junho de 1995 apenas 41\% dos entrevistados, no Brasil fazem questão da democracia em qualquer circunstância enquanto 86\% dos uruguaios e 76\% dos argentinos têm esta posição.

Verificamos portanto, que o medo e a insegurança não têm raízes diretas na criminalidade urbana. $\mathrm{O}$ medo se associa à criminalidade através de uma via simbólica. Ele surge de uma utilização político-ideológica da insegurança, e se solidifica em um ambiente de desorganização social, alienação e isolamento. $\mathrm{O}$ que significa que os dois problemas, criminalidade e medo, não se condicionam reciprocamente. A confusão, nesse caso, "serve às ideologizações, mas jamais à elaboração de política públicas eficientes” (SOARES, 1996).

Por isso mesmo, chamamos atenção para a necessidade de políticas específicas para combater a insegurança e o medo, pois eles requerem estratégias complexas, das quais o controle da criminalidade é apenas uma parte, sem dúvida indispensável. Porém, mais do que controlar a criminalidade é fundamental ampliar a comunicação entre os indivíduos, repudiando as formas de estigmatização e buscando a construção de espaços abertos comuns. A função da mídia é determinante nesse campo, assim como são decisivas as políticas sociais e culturais, e o papel das administrações e das diversas organizações e movimentos presentes na sociedade civil.

Finalizamos relembrando o sociólogo Alessandro Baratta. Para ele "a resposta ao problema da criminalidade e do medo só poderá ser efetiva, e não ilusória, se os cidadãos deixarem de ser 'espectadores' dos meios de comunicação e da política como espetáculo, para serem atores” (RAMOS, 1994), ou seja, a sociedade civil tem que se fortalecer para poder identificar seus reais problemas e a intensidade deles, bem como poder visualizar a forma mais igualitária e menos violenta de resolvê-los. Fortalecer a sociedade é um compromisso ético que Habermas (apud ZALUAR, 1997) afirmou ser a base para uma sociedade democrática.

\section{REFERÊNCIAS}

ADORNO, S. S. Cidadania e administração da Justiça criminal. In: DINIZ, E.; LEITE LOPES, S. E.; PRANDI, R. (Org.). O Brasil no rastro da crise. anuário de Antropologia, Política e Sociologia. São Paulo: Anpocs/IPEA, 1994. p. 304-327.

BATISTA, Vera Malaguti. Autoritarismo e controle social no Brasil: memória e medo. Revista Sem Terra, n. 10, 2001.

CALDEIRA, Teresa Pires do Rio. Cidade de muros: crime, segregação e cidadania em São Paulo. São Paulo: Ed.34/EDUSP, 2000.

CARDIA, Nancy. Direitos humanos: ausência de cidadania e exclusão moral. São Paulo: 
Comissão Justiça e Paz de São Paulo, 1995.

CHAUI, Marilena. Sobre o medo. In: NOVAES, Adauto (Org.). Sentidos da Paixão. São Paulo: Companhia da Letras, 1999.

. Conformismo e Resistência: aspectos da cultura popular do Brasil. São Paulo: Brasiliense, 1989.

DELUMEAU, Jean. História do medo no ocidente: 1300 - 1800. São Paulo: Companhia das Letras, 1999.

INSTITUTO DE ESTUDOS EMPRESARIAIS. Guia da Folha. São Paulo: Folha de São Paulo, 2000.

GLASSNER, Barry. The culture of Fear: why americans are afraid of the wrong things. New York: Basic Books, 1999.

KAHN, Túlio. A expansão da segurança privada no Brasil: algumas implicações teóricas e práticas. Boletim Conjuntura Criminal, ano 2, n. 5, Jun. 1999.

KAHN,T. Criminalidade e meios de comunicação. Revista Conjuntura Criminal, São. Paulo, Ago.1998

KARAM, Maria Lúcia. Aplicação da pena: por uma nova atuação da justiça criminal. Revista brasileira de ciências criminais, São Paulo, v. 2, n. 6, p 117-32, abr./jun. 1994.

MINAYO, Maria Cecília de Souza et al. A produção da (des) informação sobre violência: análise de uma prática discriminatória. Cadernos de Saúde Pública, Rio de Janeiro, v 13. n. 3, jul/set. 1997.

MOLINA, Pablos de; GARCIA, Antonio. Criminologia: uma introdução aos seus fundamentos teóricos. Tradução de Luiz Flávio Gomes. São Paulo: Revista dos Tribunais, 1992. PINHEIRO, Pulo Sérgio. et al. Continuidade autoritária e construção da democracia: Projeto integrado de pesquisa. São Paulo: NEV/USP, 1999.

PORTO, Maria do Rosário Silveira; TEIXEIRA, Maria Cecília Sanches. Violência, insegurança e imaginário do medo. Cadernos CEDES, Campinas, v.19, n. 47, dez. 1998

RAMOS, Silvia (Org.). Midia E Violência urbana. Rio de Janeiro: Faperj, 1994.

SANTOS, Boaventura de Souza. Pela mão de Alice: o social e o político na pós-modernidade. 5. ed. São Paulo: Cortez, 1999.

SGARIONI, Mariana. Folha de São Paulo, 7 nov. 1999. Caderno Cotidiano.

SOARES, Luis Eduardo. et al. Uma radiografia da violência no Rio de Janeiro. In: BENGEMER, Maria C.; BARTHOLO, Roberto S. (Org.). Violência, crime e castigo. Rio de Janeiro: Loyola, 1996.

VIANA, Maria Luiza Werneck. A Nova República e a transição entre o antigo regime e a novíssima república. Travessia, 1986.

ZALUAR, Alba. Para não dizer que não falei de samba: os enigmas da violência no Brasil" In. SCHWARCZ, Lilia Mortiz (Org.). História da Vida Privada no Brasil. São Paulo: Cia. das Letras, 2000. v.4.

. Exclusão e políticas públicas: dilemas teóricos e alternativas políticas. Revista Brasileira de Ciências Sociais, v.12, n. 35, out., 1997.

. Violência, pobreza, drogas. Braudel Papers, São Paulo, n. 12, 1995. Disponível em:〈http://www.braudel.org.br/bps/paper12b.htm>. Acesso em: out. 2005. 